
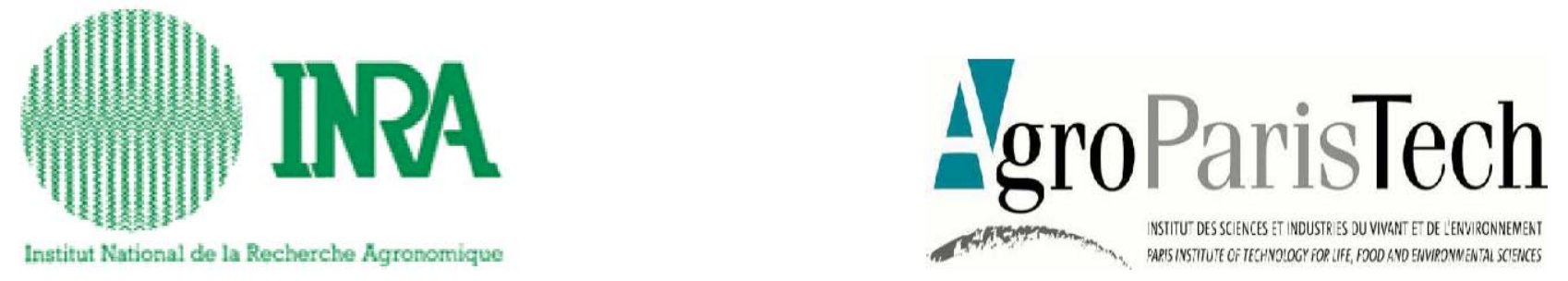

\author{
UNITE MIXTE DE RECHERCHE \\ EN ECONOMIE PUBLIQUE
}

JOINT RESEARCH UNIT IN

PUBLIC ECONOMICS

2004

CAHIERS DE RECHERCHE

WORKING PAPERS

2004/01

\title{
On Food Companies Liability for Obesity
}

\author{
B. Coestier, E. Gozlan, S. Marette
}

UMR Economie Publique

Avenue Lucien Brétignières - 78850 Grignon

16 rue Cl. Bernard - 75005 Paris

Tel. +33 (0)130815330

Fax. +33 (0)130815368

http://www.grignon.inra.fr/economie-publique 


\title{
On Food Companies Liability for Obesity.
}

\author{
Bénédicte Coestier, Estelle Gozlan and Stéphan Marette*
}

June 2004

\section{Abstract}

The US food industry faces tobacco-style lawsuits for providing misleading information about health risks linked to the consumption of fatty products. This paper investigates the link between alternative liability rules and the incentive for disclosing health information to consumers. We show that if the expected damage is relatively low, the absence of intervention is socially optimal. If the expected damage is not too high, mandatory labeling is socially optimal. Liability rules are only welfare-enhancing for high levels of risk and/or when consumers misperceive health warnings.

Key words: health risk, information, liability, negligence, regulation.

Bénédicte Coestier is maître de conférences, Department of Economics, and member, Thema, Université de Paris X, Nanterre, France. Estelle Gozlan is an economist, UMR d'Economie Publique INRA-INAPG, Paris, France. Stéphan Marette is an economist, UMR d'Economie Publique INRA-INAPG, Paris, France.

This research was conducted while Bénédicte Coestier was a visiting scholar at UMR d'Economie Publique. The authors are grateful for the comments of John Beghin, John Crespi, Norbert Wilson, two anonymous referees and seminar participants at Iowa State University and Kansas State University. All errors are ours. 


\section{Introduction}

Recent studies on the health consequences of obesity have shown that overeating may be as dangerous as smoking in terms of life expectancy (Sturm and Wells). Abuse of alcohol, cigarettes and/or fa(s)t food increases loss of human lives and health care costs. This raises the question of the best policy response through alternative instruments such as taxation, liability, information campaigns (health-warnings) or advertising restrictions. ${ }^{1}$ These policies are designed to decrease consumption, either by influencing prices, raising consumer awareness or limiting access to products. For instance, liability payments have been imposed due to the lack of information about health-risks provided by tobacco companies to consumers (Bulow and Klemperer). The US fast-food industry faces similar lawsuits for misleading advertising or absence of information about risks as we describe in the next section.

This article analyzes the complex interaction between liability, information about risks and consumer demand. Specifically, we seek to answer the question: should regulators or courts rely on health-labeling or on tort law for regulating and limiting "dangerous consumption"? This question is important since recent legal attempts to hold the US fast-food industry responsible for obesity are likely to extend to that part of the agri-business sector that produces high energy foods. To address this question, we adopt a normative approach that could provide some guidelines for regulators and/or courts.

The impacts of alternative liability rules and a mandatory labeling policy are detailed in a market context (Cournot competition) and compared with the position of a regulator who seeks to maximize welfare, taking into account profits of firms, consumer surplus and social damages. Liability rules provide (complete or partial) compensation to consumers and reduce output and profits of firms, while mandatory labeling enables 
consumers to make better choices with respect to health risks. We consider several liability rules, namely strict liability, the negligence rule and the comparative negligence rule gaining momentum in many US states. These rules allow to consider different divisions of the burden for an accident on the plaintiff and defendant, based on the revealed information or the level of preventive care.

We show that if the expected damage is relatively low, the absence of intervention is socially optimal since price/quantity distortions are avoided. In particular, informing consumers is not optimal even if the cost of information is zero. ${ }^{2}$ If the expected damage is relatively large, liability rules are not efficient for regulating the market due to the insolvency of firms. In most cases, mandatory labeling is sufficient and essential for maximizing welfare and reducing consumption (and obesity). Liability rules are essential for maximizing welfare only for high levels of risk and/or if consumers misperceive health warnings.

The literature on this topic has overlooked the links between information, insolvency of firms and market structure. Polinsky and Rogerson focus on the optimality of alternative liability rules in a market context, when consumers misperceive risks. However, they do not consider the insolvency problem, they take consumer risk perception as exogenous and they do not study the efficiency of a comparative negligence rule. Conversely, in this article, insolvency is endogenous to the market structure, which limits the efficiency of liability tools, consumer perception of risks may be improved through (mandatory or voluntary) disclosure of information, and comparative negligence may be a tailored instrument for capping consumption.

The economic literature on obesity has modeled consumer behavior and discounting issues (Cutler, Glaeser and Shapiro), but few articles have conducted a normative analysis of the public regulation issue. More generally, while many empirical 
articles focus on either the effects of taxes (Grossman, Sindelar, Mullahy and Anderson) or advertising bans (Safer and Chaloupka) for lowering any kind of "dangerous consumption", we investigate the effects of alternative instruments on market mechanisms. Daughety and Reinganum and Endres and Ludeke have shown that liability is necessary for the revelation of information to consumers. Our article departs from the former articles as we analyze alternative regulations such as voluntary/mandatory information and/or liability in a setting where firms may become insolvent in the case of a large liability payment. Moreover, we show that liability is neither essential for implementing an efficient policy nor for leading to information revelation.

The second section of the article focuses on the recent attempts to sue hamburger restaurant chains in the US, and the model is described in the third section. The main results are presented in the fourth, while the fifth provides some extensions, and the final section concludes.

\section{The Fast-Food Industry and Pending Liability}

Obesity and related illnesses are linked to some 300,000 deaths and $\$ 117$ billion in health care costs a year in the United States (Sturm and Wells), where $60 \%$ of the population is overweight with $31 \%$ considered obese (Fountain). Unhealthy food habits, together with an increasingly sedentary life style, have contributed to this situation. This could lead some states with public health problems to consider food companies as partly responsible.

Even though food habits result from conscious choices, ${ }^{3}$ one aspect of the debate on whether food companies should be held liable for obesity is misleading advertising or lack of information about risks. This is particularly true for large companies because of (1) high concentration in food manufacturing and (2) extensive advertising. Even if 
consumers may have difficulties either knowing or proving that firms are responsible for obesity, firms may be liable for misrepresentation (Banzhaf).

Lawsuits against several fast-food chains have already been filed in New York and Florida, claiming that processed foods with little nutritional value have contributed to the diabete, heart disease and obesity of the plaintiff. On July 24, 2002, a suit was filed in Bronx County, New York, against Burger King Corporation, KFC Corporation, Wendy's International and McDonald's Corporation (Barber v. McDonald Corp.). The complaint of the plaintiff is that the corporations did not adequately warn him of the health risks of eating food from their restaurants.

Recently, a US district judge dismissed an "attempt by four overweight teenagers to sue McDonald's" and decided that the potential risks were "within the common knowledge of consumers" (Buckley 2003a, pp.1). However, there is a possibility that the plaintiffs appeal against this decision. As Buckley (2003b) notes (pp.13) "the judge even suggested that the fast-food chain's Chicken McNuggets which he labelled a 'McFrankenstein creation' stuffed with additives and containing twice the fat by weight of a hamburger - might fall into that category" (of cases that could be refiled in the court). Beyond the wide skepticism about the lack of consumer awareness of the link between fast-food consumption and obesity, food companies face serious threats of lawsuits in the future. The argument is, while you cannot stop tobacco from being dangerous, you can make food less unhealthy.

In 2003, two legislative proposals that would make consumers responsible for what they eat were introduced in the U.S. Congress in order to impede obesity-related lawsuits against food manufacturers (Congress 2003, 2004). In order to receive compensation, a plaintiff would have to prove that the product was not in compliance with regulatory requirements, such as food labeling regulations. Information appears to 
be a crucial issue. Is health warnings disclosure an efficient regulatory tool? Will this regulatory tool allow food producers to avoid lawsuits?

Some firms including Coca-Cola or Unilever are voluntarily advertising to urge consumers to eat more healthily (Cozens). On the regulatory side, beyond the Nutrion Labeling and Education Act of 1990, the US Food and Drug Administration will require the amount of trans fats to be listed on all food nutrition labels by 2006 (FDA). Trans fats have been linked to raised levels of bad cholesterol and risk of heart disease, and cause 2100 to 5600 deaths in the US each year. However, the FDA has withdrawn the proposed requirement to include a footnote stating 'Intake of trans fat should be as low as possible', which would have represented a clear health warning. Danger of trans fat has received wide media coverage in 2003, and several food companies have responded to consumer concerns by changing the way they make, package and promote their food. McDonald's announced the switch to a healthier cooking oil in order to reduce the trans fat content of fried items. ${ }^{4}$ Kraft Foods plans to reduce the portion size and some calories of its products, a move that other food companies are expected to mimic (Horovitz).

The debate about the strategies of firms and the appropriate regulation will likely gain momentum. As Buckley (2003b) reports, "Food makers will have to revamp their marketing, removing advertising that promotes over-consumption and running campaigns linked with physical activity - as many companies are already doing. 'Any food company that thinks it can get through this without changing anything is kidding itself,' says the executive [of a food company]. 'You can see the collision course that is coming. It's either going to be regulation, legislation or litigation" " (pp.13). This last point directly leads to the topic of this article.

Although the judicial accountability of the food industry for obesity raises many 
questions, we focus on one central economic aspect of the debate, namely the link between information, liability and consumer demand. A simple model is proposed for measuring the impact of alternative liability rules and/or information on consumer reaction and market mechanisms (alternative assumptions will be discussed at the end of the paper). It aims at determining the second best policy, that is, the welfare maximizing regulation for a given market structure.

\section{The Model}

We consider a market with $n$ identical and risk neutral firms, selling a homogeneous product and incurring no cost of production for simplicity. These firms are aware that an overconsumption of their products may lead to obesity and they can choose whether or not to reveal some information on health risks to (risk neutral) consumers. Health warnings are costless and deliver correct information about risks, but consumers may misperceive them. ${ }^{5}$ Firms decide also on the quantity to produce in a Cournot competition context.

On the demand side, we assume an expected direct utility function of a representative consumer :

$$
U(Q, v)=u(Q)-(1-\mu)[D(Q)-F(Q)]+v,
$$

where $v$ is the numeraire, $u(Q)$ the immediate satisfaction from consuming an amount $Q$ of the good. The perceived disutility associated with the consumption of the risky product is noted as $(1-\mu)[D(Q)-F(Q)]$, where consumer misperception of risk is captured by the parameter $\mu \in[0,1]$. Both the expected damage, $D(Q)$, and the expected compensation, $F(Q)$, in case of obesity under liability are misperceived, meaning that the consumer has correct expectations about the level of compensation (related to the value of the damage), but underestimates the probability that obesity (and the subsequent compensation) occurs. Consumer misperception is assumed to be solely 
influenced by the behavior of firms with respect to their information policy: when no health warnings are disclosed by firms, consumers are completely unaware of the risks with $\mu=1$; the revelation of information by firms increases consumer perception, with a misperception parameter $\mu<1$.

From the following assumptions, (i) $u_{Q}^{\prime}>0$ and $u_{Q}^{\prime \prime} \leq 0$ (decreasing marginal satisfaction) and (ii) $D_{Q}^{\prime}>0$ and $D_{Q}^{\prime \prime} \geq 0$ (increasing expected damage), we assume the following functional forms:

- $u(Q)=a Q-\frac{Q^{2}}{2}$ is the immediate satisfaction, where a represents the consumer maximum willingness to pay for a safe product, which is consistent with (i) as long as $Q<2 a$.

- $D(Q)=(1-\lambda) d Q$ is the expected damage, where $(1-\lambda)$ denotes the exogenous average probability of becoming fat and $d$ the per-unit damage, representing the average dollar value of the reduction of life expectancy per unit of consumed food. ${ }^{6}$ The only way consumers can reduce the expected damage is by limiting their level of consumption. ${ }^{7}$

- $\quad F(Q)=(1-\lambda) f^{r} Q$ is the expected compensation, where $f^{r}$ denotes the perunit compensation which depends on the prevailing regulation and on the firms' financial situation, under the assumption $f^{r} \leq d{ }^{8}$

The maximization of (1) under budget constraint $p(Q) Q+v=y$ where $y$ denotes consumer income leads to the following inverse demand function :

$$
p(Q)=a-Q-(1-\mu)(1-\lambda)\left[d-f^{r}\right] .
$$

With respect to the regulatory environment, we restrict our attention to regulations based on liability and on information (the case for taxation will be briefly mentioned in a subsequent section). Obesity may correspond to what the law and 
economics literature considers a "bilateral accident" where prevention is possible both on the industry side (by selling reasonable quantities and/or providing information about the risks linked to the consumption of fatty foods) and on the consumer side (by having a healthy diet that is "appropriate consumption"). As appropriate behavior for consumers with respect to consumption is hard to verify, we take for granted that both sides of the market may have responsibilities in case of damage (that is declared obesity) and we therefore denote $\alpha$ as a firm's legal share of responsibility in obesity, $\alpha \in[0,1]$, and $(1-\alpha)$ remains the consumer's burden.

The parameter $\alpha$ also captures the variety of regulatory regimes we consider. Under a regime of no regulation (rule A), the whole responsibility is placed on consumers for their own obesity; $\alpha=0$. Conversely, under strict liability (rule B), firms are liable whenever obesity is declared; $\alpha=1$, whatever firms' efforts for informing consumers about risks.

Given the "bilateral accident" aspect of obesity, regimes of comparative negligence used by many US states may be advocated. Under comparative negligence (rule C), the costs linked to obesity are shared between firms and consumers, based on the level of preventive care of each party. We assume that the portion of the cost shouldered by firms depends on their information policy: the liability payment is lower if they disclose health warnings to consumers than if they do not disclose. Let $\underline{\alpha}$ be the share of responsibility linked to obesity when there is disclosure and $\bar{\alpha}$ the share of responsibility without disclosure, with $0<\underline{\alpha}<\bar{\alpha}<1$. These shares are considered as exogenous (they result from courts' past behavior) and they are public knowledge.

Negligence rule (D) describes the case where firms bear no responsibility when they provide some information. Firms bear complete responsibility when they provide no information. This rule corresponds to a limiting case of the comparative negligence 
rule, where $\underline{\alpha}=0$ and $\bar{\alpha}=1$.

Eventually, the regulator may also decide to implement a mandatory label (E) or to ban the product $(\mathrm{F})$. The policy selected by the regulator is publicly known to firms and consumers.

A four-stage oligopoly model is considered with a utilitarian regulator who maximizes welfare, accounting for profits of firms, consumer surplus and social damages. In the first stage, the regulator chooses among instruments (A) to (F). In stage 2, $n$ identical food companies simultaneously inform (or not) consumers about risks in compliance with the rule selected by the regulator. In stage 3 , following the information

decision, each firm $i$ simultaneously selects a quantity $q_{i}$ with $\sum_{i=1}^{n} q_{i}=Q$ (Cournot competition), and consumers decide on their consumption level. In stage 4 , in the case of obesity, the court imposes a liability payment consistent with the one of liability rules (B), (C) or (D) selected by the policymaker in stage 1. We assume that the court verifies without cost the overall extent of the damage $d Q$ and determines the liability share for each firm. For simplicity, we assume no litigation costs. The only assets available for compensation are the profits of the firm, which may be insufficient to cover the whole liability compensation. ${ }^{9}$

We now turn to the characterization of the subgame perfect Nash equilibrium of this four stage game (solved by backward induction) and then conduct a welfare analysis allowing the selection among the different rules.

\section{Firms' Strategies}

We successively describe the production choice and the information policy. As firms are assumed symmetric, they select the same strategy.

Output Strategy 
The output strategies of firms (in stage 3) influence their ex post solvency via the market price. With a probability $\lambda$, no damage occurs. For firm $i$, producing the output $q_{i}$, the profit is $p(Q) q_{i}$, where $p(Q)$ is the inverse demand defined in (2). With probability $(1-\lambda)$, damage occurs and firm $i$ is held responsible in proportion to its output. This leads to a liability payment $\alpha d q_{i}$, where the value of $\alpha$ depends on the regulatory regime selected in stage 1 .

If the damage occurs, the profit of the firm is either sufficient or insufficient to cover the liability payment. In the case where the profit is sufficient $(p(Q) \geq \alpha d)$, the profit is $[p(Q)-\alpha d] q_{i}$. In the case where the profit is insufficient, the firm is insolvent (or judgment proof) and its profit is completely allocated to compensation. After the liability payment, its profit is driven to zero.

Before producing, the expected profit function depends on the probabilities $\lambda$ and $(1-\lambda)$ and the (in)solvency of the firm in the case of damage. The expected profit function of firm $i$ is $\pi_{i}^{s}=[p(Q)-(1-\lambda) \alpha d] q_{i}$ if the firm expects to be solvent, and $\pi_{i}^{j p}=\lambda p(Q) q_{i}$ if it expects to be judgment proof.

The financial situation of a firm influences the expected per-unit liability payment $f^{r}$ of consumers. Consumers perfectly know the regulation and the share of responsibility $\alpha$ that is attributed to firms. Therefore, they rationally anticipate if firms may be (in)solvent for an equilibrium price depending on their risk perception. When the misperception parameter $\mu$ is relatively large, the price $p(Q)$ and the profit are relatively large and the possibility of insolvency is reduced.

For $p(Q) \geq \alpha d$ consumers expect firms to be solvent: replacing $f^{r}$ by $\alpha d$ in (2) yields the inverse demand under solvency $p^{S}(Q)$ defined in (3). Conversely if $p(Q)<\alpha d$, they expect firms to be insolvent (or judgment proof) resulting in a per-unit 
compensation equal to the market price. Replacing $f^{r}$ by $p$ in (2) gives the inverse demand function when firms are judgment proof $p^{J P}(Q)$ defined in (4):

$$
\begin{gathered}
p^{S}(Q)=a-Q-(1-\alpha)(1-\mu)(1-\lambda) d, \\
p^{J P}(Q)=\frac{a-Q-(1-\mu)(1-\lambda) d}{1-(1-\mu)(1-\lambda)} .
\end{gathered}
$$

Note that when no information is disclosed and consumers completely misperceive risks (i.e., $\mu=1), p(Q)=p^{S}(Q)=p^{J P}(Q)=a-Q$.

The expected profit function when the firm $i$ is solvent is:

$$
\pi_{i}^{S}\left(q_{i}, q_{-i} ; \alpha, \mu\right)=q_{i}\left[a-q_{i}-q_{-i}-(1-\mu+\alpha \mu)(1-\lambda) d\right]
$$

The expected profit function when the firm $i$ is insolvent is:

$$
\pi_{i}^{J P}\left(q_{i}, q_{-i} ; \mu\right)=\lambda q_{i} \frac{\left[a-q_{i}-q_{-i}-(1-\mu)(1-\lambda) d\right]}{1-(1-\mu)(1-\lambda)},
$$

with $q_{-i}$ denoting the aggregate output of other firms and $Q=q_{i}+q_{-i}$.

The profit maximization depends on the (in)solvency situation. The best reaction functions associated with these profits for the equilibria under solvency and insolvency are detailed in the appendix. To sum up, let

$$
\begin{gathered}
d_{\text {solvency }}(\alpha, \mu)=\frac{2 a}{2(1-\lambda)(1-\mu+\alpha \mu)+\alpha(1+n)[\lambda+\sqrt{\lambda(\lambda+\mu-\lambda \mu)}]}, \\
d_{\text {closure }}(\mu)=\frac{a}{(1-\lambda)(1-\mu)} .
\end{gathered}
$$

LEMMA 1. For a given regulation and a given information strategy i.e., fixed values of $\alpha$ and $\mu$, each firm selects an output $q_{i}^{S}=\frac{a-(1-\mu+\alpha \mu)(1-\lambda) d}{n+1}$ and is solvent in case of damages if $d<d_{\text {solvency }}(\alpha, \mu)$. Otherwise, it selects an output $q_{i}^{J P}=\frac{a-(1-\mu)(1-\lambda) d}{n+1}$ and is insolvent in case of damages. If $d>d_{\text {closure }}(\mu)$, output is zero if information is disclosed.

Proof: see the appendix. 


\section{Information Strategy}

In stage 2, firms decide whether or not to disclose health warnings according to the selected rule determined in stage 1. Under the absence of regulation (A) and strict liability (B), firms have no incentive to disclose health warnings, implying $\mu=1$, since it reduces the overall demand by increasing consumers' risk perception. Under a mandatory labeling (E) firms have no choice since information is compulsory.

Under comparative negligence (C) and negligence (D), the disclosure of health warnings entails two opposite effects, namely a reduction in overall demand due to increasing consumer perception of risk, and a partial or complete reduction of compensation in the case of damages. Each firm balances the two effects in its information choice, detailed in the following lemma. Let

$$
d_{\text {disclosure }}(\underline{\alpha}, \mu)=\frac{a}{(1+\sqrt{\lambda})(1-\mu(1-\underline{\alpha}))} .
$$

LEMMA 2. Under a negligence rule (with $\underline{\alpha}=0$ ) or a comparative negligence rule (with $\underline{\alpha}>0$ ), firms voluntarily release health warnings to avoid insolvency if $d<\operatorname{Min}\left[d_{\text {disclosure }}(\underline{\alpha}, \mu), d_{\text {solvency }}(\underline{\alpha}, \mu)\right]$. Otherwise no information is disclosed and firms are insolvent.

Proof: see the appendix.

\section{The optimal policy}

We now turn to the decision of a utilitarian regulator in stage 1, namely the choice of the legal environment that maximizes welfare. The regulator takes into account the equilibrium strategy of the firms (at stages 2 and 3) for choosing the best rule. The regulator choice depends on the value of the (exogenous) risk parameter $(1-\lambda)$ and on 
the risk misperception parameter $\mu$. To simplify, we characterize the optimal policy for alternative levels of risk and risk perception in separate propositions. Let

$$
\begin{gathered}
d_{1}=\frac{2 a}{(1-\lambda)(2+n+n \mu)}, \\
d_{6}=\frac{a(n+2)}{2(1+n)(1-\lambda)}, \\
\lambda_{1}=\frac{n^{2}}{(1+2 n)^{2}}, \\
\lambda_{2}=\frac{\mu^{2}[2(1+n)-\underline{\alpha}(2+n)]^{2}}{[2+(2-\underline{\alpha}) n \mu]^{2}} .
\end{gathered}
$$

The first proposition characterizes the optimal regulation (i) for low levels of risks, or

(ii) for medium levels of risks and a very good understanding of health warnings by consumers ( $\mu$ close to zero), since the threshold value $\lambda_{2}$ increases with the consumer misperception parameter $\mu$.

PROPOSITION 1. For low levels of risks, $\lambda>\operatorname{Max}\left[\lambda_{1}, \lambda_{2}\right]$, liability is not efficient and the socially optimal policy is

(i) the absence of intervention if $d<d_{1}$,

(ii) mandatory labeling if $d_{1}<d<d_{6}$,

(iii) a production ban if $d>d_{6}$.

Proof: see the appendix.

\section{[INSERT FIGURE 1]}

Figure 1 illustrates this proposition. When the value of the per unit damage $d$ is relatively low compared to the maximum per unit willingness to pay, $a$, the internalization of the damage via the price (either by solvent firms under liability or by informed consumers under labeling) is not optimal since it creates additional distortions compared to those coming from market power (depending on the number of firms). The 
absence of information impedes the internalization of the perceived expected damage $(1-\mu)(1-\lambda) d$ resulting in a quantity distortion, which is optimal when the expected damage is not too large. For low values of $d$, the absence of intervention dominates any liability rule and/or information policy (see Calabresi, and Polinsky and Rogerson). In this area, information disclosure about risk is not optimal. An information policy would lead consumers to reduce their consumption despite a relatively low expected damage, which would be inefficient.

For intermediate values of damage, information is necessary for limiting consumption and the scope of the damage linked to consumption. In the area delimited by $d_{1}$ and $d_{6}$, mandatory labeling is the best policy. ${ }^{10}$ Strict liability is not efficient since it provides no incentive for firms to disclose information, while firms prefer to be judgment proof if damage occurs (with a low probability). Neither a negligence rule nor a comparative negligence rule is efficient because when the risk is low, it does not provide sufficient incentives for firms to disclose voluntarily health warnings. Indeed mandatory labeling informs consumers and limits their consumption.

For high values of $d$, the absence of production is optimal since welfare is negative whatever the rules of intervention (A) to (E). All the alternative liability rules are inefficient because it would result in insolvent firms with no information disclosed, i.e., the same overall welfare than under no regulation, which is negative for $d>d_{6}$.

We now turn to situations with intermediate levels of risk. Let

$$
\begin{gathered}
d_{2}=\frac{2 a}{(1-\lambda)(2+n \mu(2-\underline{\alpha}))}, \\
d_{3}=\operatorname{Min}\left[d_{\text {disclosure }}(\underline{\alpha}, \mu), d_{\text {solvency }}(\underline{\alpha}, \mu)\right],
\end{gathered}
$$


PROPOSITION 2. For intermediate levels of risk (e.g. $\lambda_{1}<\lambda<\lambda_{2}$ ), the optimal policy is

(i) the absence of intervention if $d<d_{1}$;

(ii) mandatory labeling or a negligence rule if $d_{1}<d<d_{2}$;

(iii) a comparative negligence if $d_{2}<d<d_{3}$;

(iv) mandatory labeling if $d_{3}<d<d_{6}$;

(v) a production ban if $d>d_{6}$.

Proof : see the appendix

[INSERT FIGURE 2]

Figure 2 illustrates this proposition for intermediate levels of risk with relatively good consumer understanding of labels or equivalently for lower levels of risk with poor consumer understanding of health warnings $\left(\lambda_{1}<\lambda<\lambda_{2}\right)$. We focus on what happens for intermediate values of $d\left(d_{1}<d<d_{6}\right)$, since there is no difference from Figure 1 for low values of $d$ (the absence of regulation is optimal) and for very high values of $d$ (a production ban is optimal).

For $d>d_{1}$, the value of damage is high enough for the regulator to seek to reduce consumption. When $d<d_{2}$, health warnings disclosure is essential for welfare maximization and a mandatory label is equivalent to a negligence rule. However, for higher values of $d$, the decrease in consumption is not sufficient due to consumer misperception. In other words, though health warnings are disclosed, consumer internalization of the damage is lower than what would be socially efficient. Comparative negligence is the optimal regulation for $d_{2}<d<d_{3}$ : a comparative negligence rule provides the proper incentives to provide information. Health warnings disclosure does not allow firms to disclaim all responsibility in case of damage. This 
means that the damage is partially internalized by firms, and consumers reduce their consumption by the perceived uncompensated damage. Eventually, for $d>d_{3}$, consumer internalization of the damage is still insufficient, but the comparative negligence rule does not provide the proper incentives for firms to disclose health warnings. Since information allows a decrease in consumption - though lower than what would be socially efficient - the mandatory labeling rule is the optimal regulation for $d_{3}<d<d_{6}$.

So for intermediate levels of risk, it appears that liability is not crucial for regulating the market when the damage is very high or very low, but a comparative negligence rule may be welfare improving for intermediate values of $d$, due to consumer misperception and resulting imperfect internalization of the damage. Indeed, as consumer perception of risks improves $(\mu \rightarrow 0)$, mandatory labeling tends to replace comparative negligence $\left(d_{3}<d_{2}\right)$, since all the risk is internalized via better information.

We now turn to the situation with a relatively high probability of damage and consumer misunderstanding of labels, or with very high risks. Let

$$
\begin{gathered}
d_{4}=\frac{2 a}{(1-\lambda)(2+n)}, \\
d_{5}=\frac{2 a}{(1-\lambda)(2+n \mu)},
\end{gathered}
$$

PROPOSITION 3. For high levels of risk $\left(\lambda<\operatorname{Min}\left[\lambda_{1}, \lambda_{2}\right]\right)$, the optimal policy is

(i) the absence of intervention if $d<d_{4}$;

(ii) a strict liability rule if $d_{4}<d<\operatorname{Min}\left[d_{5}, d_{\text {solvency }}(1,1)\right]$;

(iii) a comparative negligence rule if $\operatorname{Min}\left[d_{5}, d_{\text {solvency }}(1,1)\right]<d<d_{6}$;

(iv) a production ban if $d>d_{6}$. 
Proof : see the appendix

\section{[INSERT FIGURE 3]}

In this case, the labeling and negligence rules are never efficient, because firms can disclaim all responsibility while consumer perception of risks does not result in correct internalization of the damage. Indeed, regulations such that the damage is at least partially internalized by firms (strict liability and comparative negligence rules) are always preferred to sole information. The efficiency of strict liability (which makes firms completely responsible for obesity) is limited by solvency of firms. For large values of $d$, the comparative negligence rule is preferred, with partial liability payments but disclosure of information.

All three propositions hold under imperfect competition (Cournot setting with $n$ firms). The case for a competitive situation may be captured by allowing $n$ to go to infinity. When $n \rightarrow+\infty$, firms profits tend towards zero, so that strict liability, negligence rule or comparative negligence are inefficient for reducing the production of firms. ${ }^{11}$ In this case, mandatory labeling would be selected for $d<d_{6}$ and a production ban would be selected for $d>d_{6}$.

\section{Extensions}

In defining the analytical framework, very restrictive assumptions were made for simplicity. Some of the results of the model are robust if we consider the following extensions.

(i) In the model, we abstracted from any labeling or litigation cost. A complete cost-benefit analysis should take into account the cost of determining the optimal regulation to mitigate obesity and related damages. Our results have to be adjusted to allow for administrative costs. A positive cost of liability (information) reinforces the 
argument for information policy (liability). Our results which relate the insolvency of firms to price/quantity distortions are always a factor in the definition of the optimal regulation.

(ii) We assumed that the court was able to determine the liability share of each firm. Even if this assumption is dropped, it is easy to make the liability payment proportional to firms' market share (which is the same for each firm under our symmetric setting). Without completely knowing the responsibility of each firm, the court may equally allocate liability to symmetric firms. ${ }^{12}$ An alternative solution to liability could be a trust fund for compensating victims or financing information policy, avoiding litigation costs and complex procedures for determining precise responsibilities. The companies could put money into a trust fund according to their profits.

(iii) Throughout the model, we assumed that the regulator was acting in the public's best interest. One stumbling block for such regulatory "fairness" is the efficiency of the public regulatory authority itself. Public agencies may be doomed to failure if their mandate is not clearly defined or they suffer from excessive bureaucracy. Also, we assumed that the regulator and court act with perfect information about firm characteristics or damage. Another extension could examine, first, the consequences of imperfect information about damage, which may reduce the efficiency of liability due to the cost of inspection and/or expertise, and second, the consequences of misleading messages regarding the risks.

(iv) The probability of damage $(1-\lambda)$ was exogenous in the model. The results of the paper would be reinforced if we were to consider a more realistic assumption that the probability depends on consumer' effort. The relevant liability rule would then be the contributory negligence defense which imposes no liability on firms if consumers 
fail to collect enough information for taking due care. The absence of compensation paid by firms would lead consumers to be responsible for their food consumption behavior. $^{13}$

(v) The probability of damage $(1-\lambda)$ was assumed homogenous among consumers. Consumers may vary in their risks of becoming obese. Consumption behaviors are related to the level of income, education... Our results may hold for heterogenous consumers by assuming different levels of risk among consumers. Proposition 1 with $\lambda>\operatorname{Max}\left[\lambda_{1}, \lambda_{2}\right]$ may characterize some market reactions coming from less risky consumers, while the proposition with $\lambda<\operatorname{Min}\left[\lambda_{1}, \lambda_{2}\right]$ may characterize some market reactions coming from risky consumers. One solution for dealing with consumer heterogeneity is to develop targeted information campaigns. Also, we assumed that the misperception parameter $\mu$ was the same for every consumers. The perception of messages on risks may vary among the population notably with the age. Results would be easely derived for each "class of population".

(vi) We only focused on the consumption of one type of good, where demand is influenced by the internalization of consumer losses. An extension would consider demands for different types of goods, namely high-fat or low-fat products, with some imperfect substitutability among these goods. In such a setting, the demand for high-fat products would decrease under the internalization of the loss (as in our model), leading to an increase in the demand for low-fat products. This substitution of low-fat for highfat may be evaluated through econometric estimation, taking into account a complete basket of food products.

(vii) The key point of this model was the effect of liability/information systems on consumer demand, since any regulation aims at affecting consumption. Our analysis should be extended through econometric evaluation regarding the reaction of demand to 
price variation and/or to information. In our model, we assumed that mandatory labeling shifts the misperception parameter from $\mu=1$ to $\mu<1$. For the tobacco industry, several studies have shown that information campaigns did not have a significant effect on consumption, see, e.g., Sloan, Smith and Taylor, whereas empirical evidence shows that consumers mainly respond to prices. In contrast, Modjuska and Caswell show that mandatory labeling on nutritional quality influences demand in the US. However, if information disclosure is relatively inefficient for reducing demand (with a misperception parameter $\mu<1$ but close to one) and liability is inoperative due to insolvency, a tax could be useful. Once more, tax efficiency would depend on the demand price-elasticity. A complete cost-benefit analysis would consider the possible combination of all these instruments.

(viii) Throughout the model, we abstract from taxation, while levies on fatty foods or a tax on calories could be used. However, such a tax could be perceived as a regressive tax because it hurts people with healthy behaviors, and people on lower incomes tend to eat proportionally larger quantities of cheap, high-fat food. In our setting, a per-unit tax equal to the per-unit damage (and passed on to consumers via the price) may be imposed by the regulator if, either liability tools entail insolvency or the information policy is unable to improve consumer perception of risk. This tool is a substitute for the instruments presented in this article.

\section{Conclusions}

The central economic issue in this article was the effect of liability/information systems on consumer demand. Different rules and their possible combinations were compared from a regulator point of view. We showed that if the expected damage is relatively low, the absence of intervention is socially optimal. While, if the expected damage is 
relatively large, health warnings are necessary for reaching the optimal social choice. Indeed, liability rules are essential for bringing about lower consumption of risky products only if consumers misperceive health warnings. This confirms the recent decision of the US district judge that dismissed an attempt to sue McDonald's.

\section{References}

Banzhaf J. March 2003. Available at http://banzhaf.net/obesitylinks.

Barber v. McDonald Corp., Index \#23145/2002, N.Y. Sup. Ct. Bronx Cty, July 24, 2002.

Baumol, W. "On Taxation and the Control of Externalities." American Economic Review 62(1972):307-22.

Buchanan J. "External diseconomies, corrective taxes, and market structure." American Economic Review 59(1969):174-77.

Buckley N. "McDonald's Suit Thrown Out." Financial Times, January 22, 2003. Available at http://news.ft.com, pp.1.

. "Unhealthy Food is Everywhere, 24 Hours a Day, and Inexpensive." Financial Times, February 18, 2003, pp.13.

Bulow J. and P. Klemperer. "The Tobacco Deal." Brookings Papers on Economic Activity Microeconomics 1998, The Brookings Institution.

Calabresi G. "Some Thoughts on Risk Distribution and the Law of Torts." Yale Law Journal 70 (1961): 499-553.

Cozens C. "McDonald's and Coke fund healthy eating drive." The Guardian, June 14, 2002. Available at http://www.guardian.co.uk/Archive/Article/0,4273,4433657,00.html

Cutler M., E.L. Glaeser and J. Shapiro. "Why Have Americans Become More Obese?" Journal of Economic Perspectives 17(2003):93-118. 
Daughety A. and J. Reinganum. "Everybody Out of the Pool: Products Liability, Punitive Damages, and Competition." Journal of Law, Economics and Organization 13(1997):410-32.

Elbasha E. and T. Lynn Riggs. "The effects of information on producer and consumer incentives to undertake food safety efforts: A theoretical model and policy implications.” Agribusiness 19(2003):29-42.

Endres A. and A. Ludeke. "Incomplete Strict Liability: Effects on Product Differentiation and Information Provision." International Review of Law and Economics 18(1998):511-28.

Fountain H. "In the Land of Plenty, Americans Grow Fatter." The New York Times, October 18, 2002, pp.8.

Grossman, M., J.L. Sindelar, J. Mullahy, and R. Anderson. "Policy watch: Alcohol and cigarette taxes.” Journal of Economic Perspectives 7(1993):211-22.

Horovitz B. "Kraft plans to start putting its food on a diet." USA Today, July 7, 2003. Available at http://www.usatoday.com/money/industries/food/2003-07-01-kraft $\backslash$ x.htm.

Malaith, G., M. Okino-Fujiwara and A. Postlewaite, "Belief Based Refinments in Signaling Games. ” Journal of Economic Theory 60 (1993):241-275.

Marette S., Coestier B. and E. Gozlan, "The Magnitude of Penalty and the JudgmentProof Problem.” Working paper, UMR Economie Publique INRA-INAPG, Paris, 2003.

Modjuska E. and J. Caswell. "A Test of Nutritional Quality Signaling in Food Markets Prior to Implementation of Mandatory Labeling." American Journal of Agricultural Economics 82(2000):298-309.

Polinsky A. M. and W. Rogerson. "Products Liability and Consumer Misperceptions and Market Power." The Bell Journal of Economics14(1983):581-89. 
Safer H. and F. Chaloupka. "The Effects of Tobacco Advertising Bans on Tocabbo Consumption." Journal of Health Economics19(2000): 1117-37.

Sloan F., V. K. Smith and D. H. Taylor. "Information, addiction, and 'bad choices': lessons from a century of cigarettes.” Economics Letters 77(2002):147-55.

Sturm R. and K. Wells. "Does Obesity Contribute As Much to Morbidity As Poverty or Smoking?" Public Health 115(2001):229-95.

United Nations, World Health Organization (WHO). Technical Report Series 916, Diet, Nutrition and the Prevention of Chronic Diseases. Report of a joint WHO/FAO expert consultation, Geneva, 2003.

U.S. Congress. Senate, Commonsense Consumption Act. Washington DC: 108th Cong., 1st sess., S1428, July 17, 2003.

. Senate, Personal Responsability in Food Consumption Act. Washington DC: 108th Cong., 2nd sess., HR 339, March 26, 2004.

U.S. Food and Drug Administration (FDA). National Academy of Sciences, Institute of Medicine, Letter Report on Trans Fatty Acids: FDA's Next Steps. Washington DC, July 2002. Available at http://vm.cfsan.fda.gov/ dms/labtrans.html.

\section{APPENDIX}

Proof of Lemma 1 : Firms'output strategy

For each firm $i$, the objective function is given by (5) if the firm expects to be solvent, and by (6) if the firm expects to be judgment proof. Under solvency, firm $i$ 's best reaction output to the aggregate output of other firms $q_{-i}$ (with $Q=q_{i}+q_{-i}$ ) is 


$$
b_{i}^{S}\left(q_{-i} ; \alpha, \mu\right)=\frac{a-(1-\lambda)(1-\mu+\alpha \mu) d-q_{-i}}{2} .
$$

Under a symmetric Cournot setting, if all firms turn to the solvent output strategy, each firm selects an output $q_{i}^{S *}(\alpha, \mu)=\operatorname{Max}\left[\frac{a-(1-\lambda)(1-\mu+\alpha \mu) d}{n+1}, 0\right]$, the market price is $p^{S *}=\frac{a-(1-\lambda)[(1-\mu)(1-\alpha)-n \alpha] . d}{n+1}$ and the maximized profits that firms expect under solvency is

$$
\pi^{S *}(\alpha, \mu)=\left[\frac{a-(1-\lambda)(1-\mu+\alpha \mu) d}{1+n}\right]^{2} .
$$

Conversely, if firm $i$ expects to be insolvent, its best reaction to the aggregate output of other firms $q_{-i}$ is

$$
b_{i}^{J P}\left(q_{-i} ; \alpha, \mu\right)=\frac{a-(1-\lambda)(1-\mu) d-q_{-i}}{2},
$$

which leads, under a symmetric Cournot setting, to a per-firm output $q_{i}^{J P *}(\alpha, \mu)=\operatorname{Max}\left[\frac{a-(1-\lambda)(1-\mu) d}{n+1}, 0\right]$ and to a market price $p^{J P *}=\frac{a-(1-\lambda)(1-\mu) d}{(n+1)(\lambda+\mu-\lambda \mu)}$. The maximized profits that firms expect under insolvency is

$$
\pi^{J P *}(\mu)=\frac{\lambda[a-(1-\lambda)(1-\mu) d]^{2}}{(\lambda+\mu-\lambda \mu)(1+n)^{2}} .
$$

Solvency yields higher profits than insolvency if $\pi^{S *}(\alpha, \mu)>\pi^{J P *}(\mu)$ for $d<\frac{a}{1-(1-\alpha)(\lambda+\mu-\lambda \mu)+\alpha \sqrt{\lambda+\mu-\lambda \mu}}$. However solvency is an equilibrium strategy only if each firm $i$ 's best reaction to other firm's solvent strategy is to be solvent. Indeed there is an incentive for deviation if $\pi_{i}^{J P}\left(b_{i}^{J P}\left(q_{-i}^{S *}\right), q_{-i}^{S *}\right)>\pi_{i}^{S}\left(b_{i}^{S}\left(q_{-i}^{S *}\right), q_{-i}^{S *}\right)$ where the expressions of the profit functions $\pi_{i}^{S}\left(q_{i}, q_{-i}\right)$ and $\pi_{i}^{J P}\left(q_{i}, q_{-i}\right)$ are given respectively by (5) and (6). This is true (each single firm prefers to be insolvent when expecting the others to be solvent) for $d>d_{\text {solvency }}(\alpha, \mu)$ defined in (7). It is easy to show that $\frac{a}{1-(1-\alpha)(\lambda+\mu-\lambda \mu)+\alpha \sqrt{\lambda+\mu-\lambda \mu}}>d_{\text {solvency }}(\alpha, \mu)$ which means that for values of $d$ between these two values each individual firm has an incentive to deviate from solvency, and all firms 
do so, resulting in insolvency, though profit of each firm would be higher under solvency. For high values of $d>d_{\text {closure }}(\mu)$ defined in (8), the output $q_{i}^{J P *}(\alpha, \mu)$ is 0 , provided that consumers do not completely misperceive risks, that is $\mu \neq 1$ ( information is disclosed).

Note that for $d<d_{\text {solvency }}(\alpha, \mu)$ and for $d$ not too small, another equilibrium is possible, where all sellers are judgment proof. This is a situation of multiple equilibria (see Marette, Coestier and Gozlan, 2003). The solvency equilibrium is selected according to the Mailath, Okino-Fujiwara and A. Postlewaite refinement criterion, where firms select the equilibrium leading to the highest profit. For $d<d_{\text {solvency }}(\alpha, \mu)$ and for $d$ not too small, the profit $\pi_{i}^{S}\left(q_{i}, q_{-i}\right)$ is greater than $\pi_{i}^{J P}\left(q_{i}, q_{-i}\right)$, leading to the solvency equilibrium.

\section{Proof of Lemma 2 : Firms' information strategy}

Under comparative negligence (C), each firm's share of responsibility for the damage is $\bar{\alpha}$ without information, and $\underline{\alpha}<\bar{\alpha}$ if health warnings are disclosed. Negligence is a particular case of comparative negligence with $\bar{\alpha}=1$ and $\underline{\alpha}=0$, so we will only detail information choice under a comparative negligence rule.

In stage 2 , if firms disclose information, they anticipate to be solvent in stage 3 for $d<d_{\text {solvency }}(\underline{\alpha}, \mu)$; if they disclose no information, they expect to be solvent in stage 3 for $d<d_{\text {solvency }}(\bar{\alpha}, 1)$. Since $d_{\text {solvency }}(\bar{\alpha}, 1)<d_{\text {solvency }}(\underline{\alpha}, \mu)$, three situations may arise :

(i) For low values of $d$ with $d<d_{\text {solvency }}(\bar{\alpha}, 1)$, firms expect to be solvent whatever their information strategy. They have an incentive to disclose health warnings 
if $\pi^{S *}(\underline{\alpha}, \mu)>\pi^{S *}(\bar{\alpha}, 1)$, where the expression of $\pi^{S *}$ comes from (A.2). This is true for $d<\frac{2 a}{(1-\lambda)(1+\bar{\alpha}-\mu(1-\underline{\alpha}))}$ which is greater than $d_{\text {solvency }}(\bar{\alpha}, 1)$, so that firms always disclose information when they expect to be solvent.

(ii) For $d_{\text {solvency }}(\bar{\alpha}, 1)<d<d_{\text {solvency }}(\underline{\alpha}, \mu)$, firms expect to be solvent if they disclose health warnings, and judgment proof if not. They have an incentive to disclose information if $\pi^{S *}(\underline{\alpha}, \mu)>\pi^{J P *}(1)$ where the expression of $\pi^{S *}$ comes from (A.2) and expression of $\pi^{J P *}$ comes from (A.4). This is true for $d<d_{\text {disclosure }}(\underline{\alpha}, \mu)$ defined in (9).

(iii) For $d>d_{\text {solvency }}(\underline{\alpha}, \mu)$, firms expect to be insolvent in any case and would disclose information if $\pi^{J P *}(\mu)>\pi^{J P *}(1)$; however this scenario is impossible when $d>d_{\text {solvency }}(\underline{\alpha}, \mu)$. This result holds for values of $d$ above the threshold value $d_{\text {closure }}(\mu)$ defined in (8) for which the optimal output for an insolvent firm disclosing information is zero, i.e., a firm that expects insolvency never discloses information.

So conditions (i), (ii) and (iii) can be summed up in lemma 2, where information is disclosed for $d<d_{\text {disclosure }}(\underline{\alpha}, \mu)$, provided that this threshold value is within the area where information allows firms to be solvent (i.e., $\left.d_{\text {disclosure }}(\underline{\alpha}, \mu)<d_{\text {solvency }}(\underline{\alpha}, \mu)\right)$. If not, information is disclosed for $d<d_{\text {solvency }}(\underline{\alpha}, \mu)$.

\section{Welfare}

Welfare is defined as the sum of expected consumer surplus and expected profits, adjusted for the expected part of the overall loss that is neither compensated by firms nor internalized by consumers in their demand function due to their misperception of risk. Expected consumer surplus, $\int_{0}^{Q^{*}} p(Q) d Q-p\left(Q^{*}\right) Q^{*}$ is $\frac{Q^{* 2}}{2}$ if firms are solvent 
(when integrating the inverse demand function defined in (3)), and $\frac{Q^{* 2}}{2 \lambda}$ if firms are judgment proof (when integrating the inverse demand function defined in (4)).

Firms' legal per-unit compensation is $\alpha d$. Under solvency, consumers rationally expect that a part $(1-\alpha)$ of the damage remains uncompensated. However since their perception of the probability of damage is $(1-\mu)(1-\lambda)<(1-\lambda)$, their internalization of the uncompensated damage is incomplete and a part $\mu(1-\lambda)(1-\alpha)$ of the per-unit damage remains omitted both in profits and consumer surplus. Thus the welfare function is $W^{S}(Q, \alpha, \mu)=n \Pi^{S}+\frac{\left(Q^{S}\right)^{2}}{2}-\mu(1-\lambda)(1-\alpha) d Q^{S}$. Replacing $Q^{S}$ by $n q_{i}^{S *}(\alpha, \mu)$ and $\Pi^{S}$ by $\pi^{S *}(\alpha, \mu)$ yields the welfare with solvent firms as a function of $\alpha$ and $\mu$ : $W^{S}(\alpha, \mu)=\frac{n}{2(n+1)^{2}}[a-(1-\lambda)(1-\mu+\alpha \mu) d][(n+2)(a-(1-\lambda) d)-n(1-\alpha) \mu(1-\lambda) d]$ When firms are insolvent, the uncompensated part of the per-unit damage is $d-p$. Due to consumer misperception of the probability of damage, a part $\mu(1-\lambda)(d-p) Q$ of the total damage remains omitted from profits and consumer surplus. Thus the welfare function is $W^{J P}(Q, \alpha, \mu)=n \Pi^{J P}+\frac{\left(Q^{J P}\right)^{2}}{2}-\mu(1-\lambda)\left(d-p^{J P}\right) d Q^{J P}$. Replacing $Q^{J P}$ by $n q_{i}^{J P *}(\mu)$ and $\Pi^{J P}$ by $\pi^{J P *}(\mu)$ yields the welfare with judgment proof firms as a function of $\mu$ :

$W^{J P}(\mu)=\frac{n[a-(1-\lambda)(1-\mu) d][(n+2(\lambda+\mu-\lambda \mu))(a-(1-\lambda) d)+n \mu\{2(1-\lambda)(1-\mu)-1\}(1-\lambda) d]}{2(n+1)^{2}(\lambda+\mu-\lambda \mu)}$

Welfare depends on the liability regime, and the information and solvency strategies of firms. When no regulation is implemented $(\alpha=0)$, no information is disclosed $(\mu=1)$ and firms are solvent, so that welfare is

$$
W_{\text {NoRule }}=W^{S}(0,1)
$$


Under a strict liability rule $(\alpha=1)$, no information is disclosed $(\mu=1)$ and firms' output strategy determines solvency.

$$
W_{\text {Strict }}=\left\{\begin{array}{lc}
W^{S}(1,1) & \text { if } d \leq d_{\text {solvency }}(1,1)=\frac{2 a}{(1+\sqrt{\lambda})(2+(n-1) \sqrt{\lambda})} \\
W^{J P}(1) & \text { else }
\end{array}\right.
$$

where $d_{\text {solvency }}(\alpha, \mu)$ is defined in (7).

Under a negligence rule, firms disclose health warnings $(\mu<1)$ and are solvent $(\underline{\alpha}=0)$ for low values of $d$, but disclose no health warnings $(\mu=1)$ and are insolvent $(\bar{\alpha}=1)$ for high values of $d$ :

$$
W_{\text {Negligence }}= \begin{cases}W^{S}(0, \mu) \text { if } d \leq d_{\text {disclosure }}(0, \mu)=\frac{a}{(1+\sqrt{\lambda})(1-\mu)} \\ W^{J P}(1) & \text { else }\end{cases}
$$

where $d_{\text {disclosure }}(\alpha, \mu)$ is defined in (9).

Under a comparative negligence rule, firms disclose health warnings $(\mu<1)$ and are solvent $(\underline{\alpha}>0)$ for low values of $d$, but disclose no health warnings $(\mu=1)$ and are insolvent $(\bar{\alpha}>\underline{\alpha})$ for high values of $d$ :

$$
W_{\text {Comparative }}=\left\{\begin{array}{c}
W^{S}(\underline{\alpha}, \mu) \text { if } d \leq d_{3}(\underline{\alpha}, \mu) \\
W^{J P}(1) \quad \text { else }
\end{array}\right.
$$

where $d_{3}(\underline{\alpha}, \mu)$ is defined in (15).

Note that $W^{J P}(1)=W^{S}(0,1)$, meaning that for the utilitarian regulator, implementing a liability rule when firms would be insolvent and disclose no information is equivalent to implementing no regulation.

Eventually, if a mandatory label is implemented, health warnings are disclosed whatever the value of $d$ resulting in a market closure for high values of the damage. With $\alpha=0$, firms are always solvent and the welfare is 


$$
W_{\text {Label }}=\left\{\begin{array}{c}
W^{S}(0, \mu) \text { if } d \leq d_{\text {closure }}(\mu) \\
0
\end{array}\right.
$$

where $d_{\text {closure }}(\mu)$ is defined in (8). Indeed a negligence rule (D) and a label (E) result in the same welfare for low values of $d$, with information disclosed and no liability payment. For $d>d_{\text {disclosure }}(0, \mu)$, the negligence rule fails to provide sufficient incentives for firms to disclose health warnings voluntarily.

\section{The frontiers determination and proof of propositions}

The frontier $d_{4}$ defined in (16) comes from the comparison of $W^{S}(0,1)$ and $W^{S}(1,1)$ with $W^{S}(0,1)>W^{S}(1,1) \Longleftrightarrow d<d_{4}$.

The frontier $d_{5}$ defined in (17) comes from the comparison of $W^{S}(1,1)$ and $W^{S}(0, \mu)$ with $W^{S}(1,1)>W^{S}(0, \mu) \Longleftrightarrow d<d_{5}$.

The frontier $d_{1}$ defined in (10) comes from the comparison of $W^{S}(0, \mu)$ and $W^{J P}(1)$ with $W^{S}(0, \mu)>W^{J P}(1) \Longleftrightarrow d>d_{1}$.

The threshold value $\lambda_{1}$ defined in (12) comes from the comparison of $d_{\text {solvency }}(1,1)$ and $d_{4}$.

So a strict liability rule when the regulator expects firms to be solvent is preferred to any other regulation for $d_{4}<d<d_{5}$. The constraint that $d_{4}<d_{5}$ is always true. However under strict liability, firms choose to be solvent only if $d \leq d_{\text {solvency }}(1,1)$. When the risk of obesity is relatively low with $\lambda>\lambda_{1}, d_{\text {solvency }}(1,1)<d_{4}$ meaning that strict liability is never optimal. Conversely for very high risks $\left(\lambda<\lambda_{1}\right)$, strict liability is the optimal 
regulation for $d_{4}<d<\operatorname{Min}\left[d_{5}, d_{\text {solvency }}(1,1)\right]$.

Since $d_{1}<d_{4}$, the absence of regulation is always the optimal regulation for $d<d_{1}$ (remember that $\left.W^{J P}(1)=W^{S}(0,1)\right)$. Conversely when $d>d_{1}$ information is preferred (but may be dominated by a strict liability rule for very high risks).

The frontier $d_{2}$ defined in (14) comes from the comparison of $W^{S}(0, \mu)$ and $W^{S}(\underline{\alpha}, \mu)$ with $W^{S}(0, \mu)>W^{S}(\underline{\alpha}, \mu) \Longleftrightarrow d<d_{2}$.

The threshold value $\lambda_{2}$ defined in (13) comes from the comparison of $d_{2}$ and $d_{3}$.

Since $d_{1}<d_{2}\left(<d_{5}\right)$, a mandatory label is optimal for $d_{1}<d<d_{2}$ when the risk of obesity is relatively low (with $\lambda>\lambda_{1}$ ). A negligence rule may result in the same welfare provided that firms disclose information with $d \leq d_{\text {disclosure }}(0, \mu)$, but this is true when the risk is not too low.

For $d>d_{2}$, comparative negligence is preferred to a label (or a negligence rule), provided that information is disclosed with $d \leq d_{3}$, but this is true when the risk is high enough (for $\left.\lambda<\lambda_{2}=\frac{\mu^{2}(2(1+n)-\underline{\alpha}(2+n))^{2}}{(2+n \mu(2-\underline{\alpha}))^{2}}\right)$. Note that the threshold value $\lambda_{2}$ is zero when $\mu=0$, meaning that there is no role for a comparative negligence when a label brings perfect information, i.e., there is no residual misperception), while it is greater than 1 when $\mu=1$.

The frontier $d_{6}$ defined in (11) comes from the condition of $W^{S}(0,1)=W^{J P}(1)>0$ which holds for $d<d_{6}$.

The inequalities $d_{1}<d_{4}<d_{5}$ and $d_{1}<d_{2}<d_{5}$ are always true. 


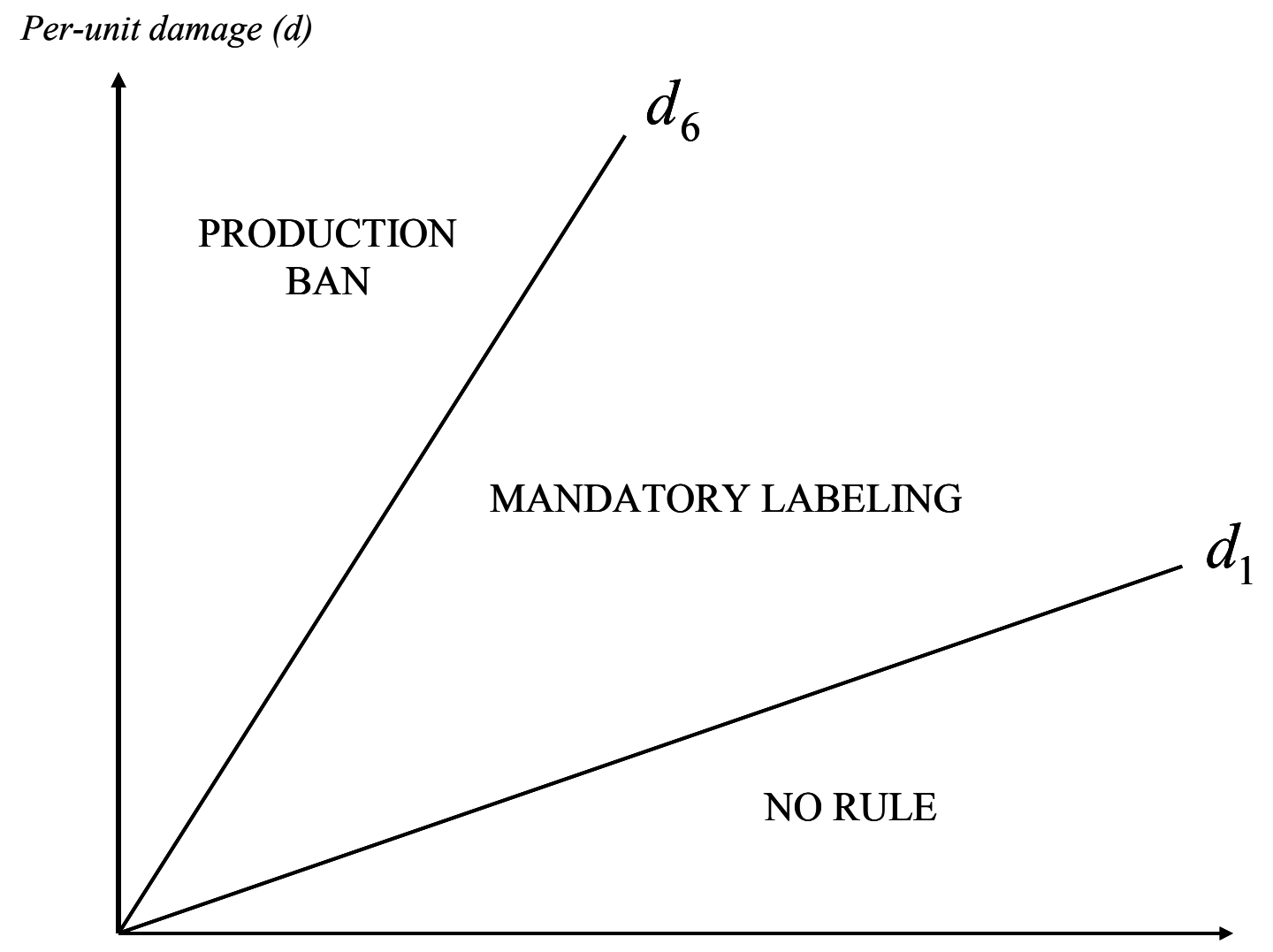

Maximum willingness to pay in the absence of risk or risk perception (a)

Figure 1. Optimal Regulation for Low Levels of Risk 


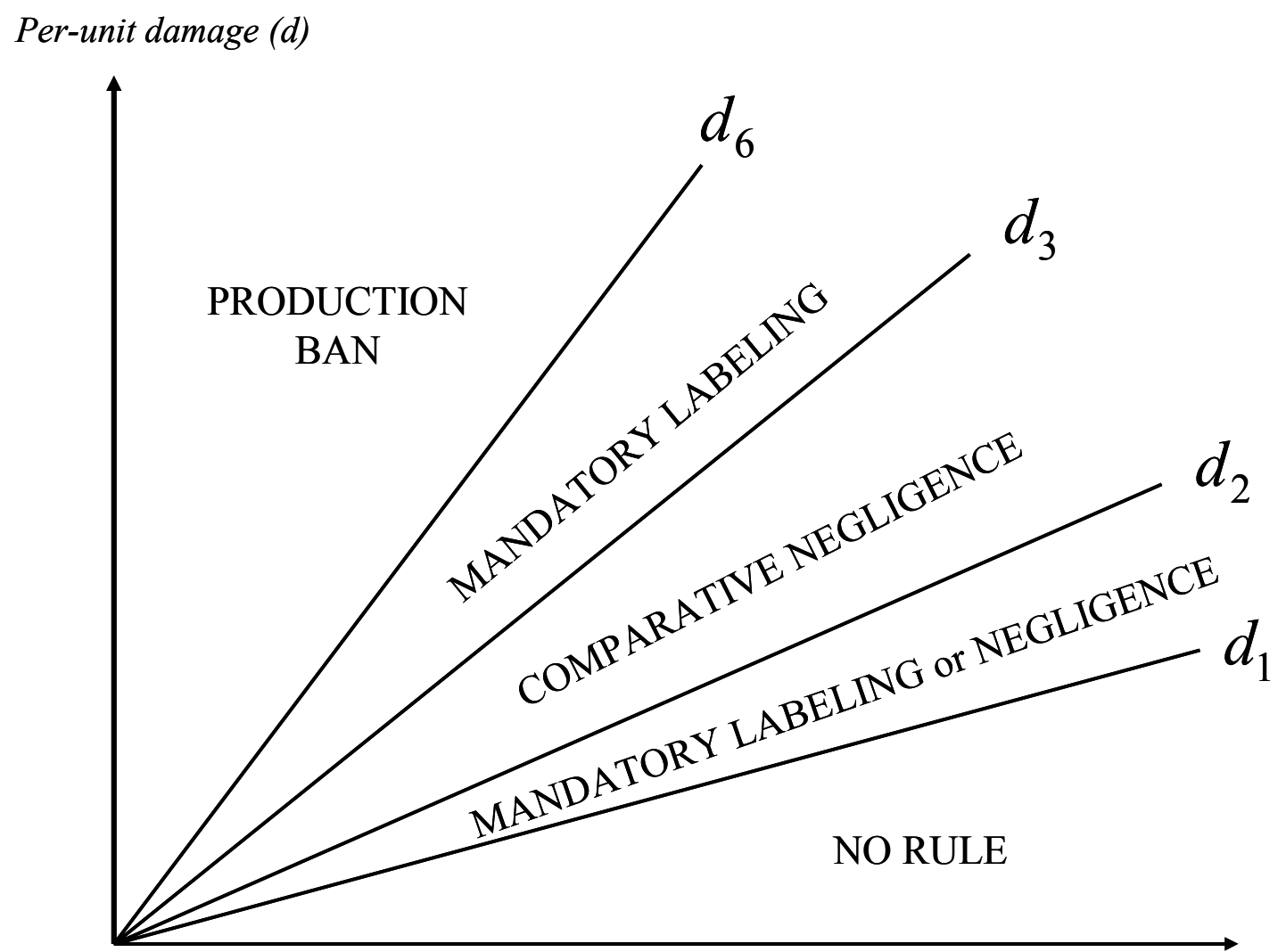

Maximum willingness to pay in the absence of risk or risk perception (a)

Figure 2. Optimal Regulation for Intermediate Levels of Risk 


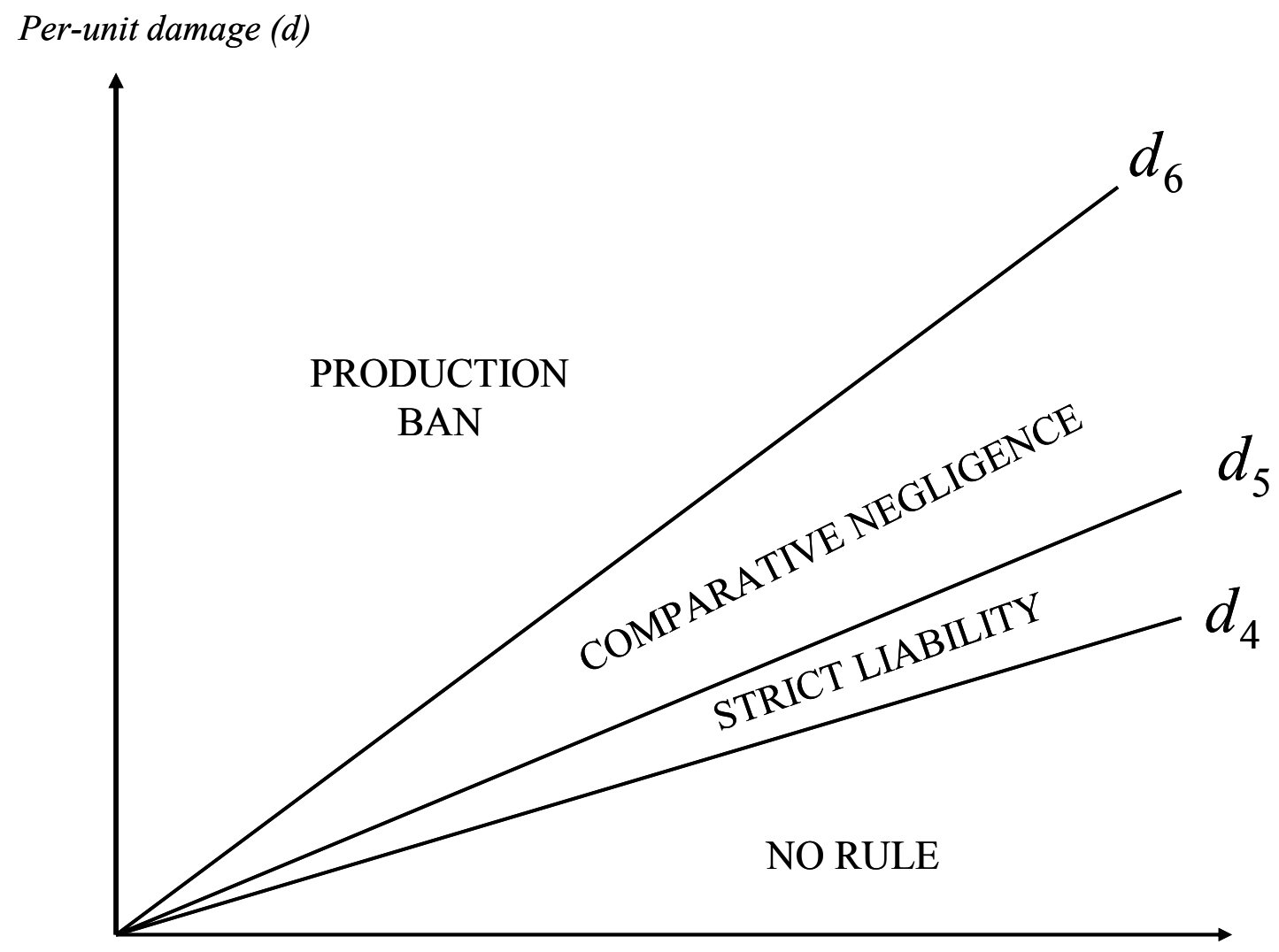

Maximum willingness to pay in the absence of risk or risk perception (a)

Figure 3. Optimal Regulation for High Levels of Risk 
${ }^{1}$ This question is particularly relevant for many developing countries where food policies remain focused on malnutrition, neglecting the prevention of chronic diseases (WHO).

${ }^{2}$ This is consistent with the traditional results on the regulation of externalities under imperfect competition, see for example Buchanan, Baumol, etc.

${ }^{3}$ As Buckley (2003b) notes "food, unlike tobacco, is essential to life, safe in moderation and not generally considered addictive. Consumers are free to eat what they choose and are aware that some foods are less healthy than others".

${ }^{4}$ However BanTransFats.com, a California non-profit corporation, has filed a lawsuit against McDonald's in October 2003 for "false advertising regarding its announcement that it was implementing a change to a new cooking oil with $48 \%$ less trans fat, and that the change would be completed by February 2003 ". It asks the court to order McDonald's take effective steps to inform its customers about its failure to make the change.

${ }^{5}$ Even when consumers read labels, they do not always understand them, due to lack of time or education for instance.

${ }^{6}$ This simplifying assumption will be discussed at the end of the article.

${ }^{7}$ Note that $1-\lambda$ could be equally well defined as the product of the probability of becoming fat and a discount factor. In that case, $D(Q)$ corresponds to the present value of the expected monetary cost linked to obesity.

${ }^{8}$ The assumption $f^{r} \leq d$ means that compensation will never exceed the social cost of damage. Observe that with this assumption, we limit moral hazard phenomenon on consumer side whereby a consumer would deliberately overconsume the product in order to obtain indemnification.

${ }^{9}$ Owner's equity in a firm is equal to the accumulation of past net profits (integrating the reimbursements of debts).

${ }^{10}$ Negligence may allow the same welfare as a mandatory label, provided that firms have an incentive to disclose information for $d<d_{\text {disclosure }}(0, \mu)$. However, when the risk is very low, $d_{\text {disclosure }}(0, \mu)<d_{1}$ so that labeling is the only way to have health warnings disclosed by firms. For higher values of the risk, it is possible that $d_{1}<d_{\text {disclosure }}(0, \mu)<d_{6}$, so that a mandatory labeling rule and a negligence rule are 
equivalent, at least for some values of $d$.

${ }^{11}$ This result also emerges under Bertrand competition with a number of firms greater or equal to two.

${ }^{12}$ This may include class action liability where all the industry has to pay $d Q$ to the victims, where $Q$ denotes the overall level of production of the industry. This overall penalty can be shared among firms according to their production $q_{i}$, which leads to a per-firm payment equal to $d q_{i}$.

${ }^{13}$ Probability $(1-\lambda)$ may also depend on the firm's effort by the choice of better-quality ingredients, see, e.g., Elbasha and Lynn Riggs. It is possible to extend our results, where $\lambda$ depends on firms' effort. Firms' incentives to invest in prevention or quality could be diluted under potential insolvency linked to liability. 